\title{
Modelling ecological specificities of freshwater molluscs: the exemplary case of Bythinella austriaca (v. Frauenfeld, 1857) (Gastropoda, Prosobranchia)
}

\author{
Robert STURM* \\ Brunnleitenweg 41, A- 5061 Elsbethen, Salzburg, Austria \\ *Corresponding author: Robert.Sturm@stud.sbg.ac.at
}

\begin{abstract}
Main objective of the study was the description of Weighted Average Analysis (WAA) as appropriate mathematical method for modelling the demands of freshwater molluscs on their habitats. With this approach site-specific environmental factors defining a certain biotope are weighted by the related population density of a selected organism. This allows the determination of optimum ranges of physical and chemical factors, within which highest probabilities of occurrence of the investigated organism may be expected. As an exemplary case ecological demands of the Austrian spring snail, Bythinella austriaca, were modelled by using WAA. In addition, a global marginality coefficient, which reflects the ability of the gastropod to occupy ecological niches, and a global tolerance coefficient, describing the width of the niche colonized by the organism, were computed for 10 selected environmental factors. As suggested by the modelling results, B. austriaca exhibits specialist behaviour with regard to water temperature, electric conductivity, dissolved oxygen, total water hardness, geographic altitude, biological oxygen demand, current velocity, and dissolved nitrate. Furthermore, the gastropod only tolerates small to intermediate fluctuations of these environmental factors, which remarkably reduces its ability to act as a pioneer species.
\end{abstract}

Key words: Weighted average analysis; habitat requirements; spring snail; ecological model; indicator organism; gastropod.

Received: March 2016. Accepted: July 2016.

\section{INTRODUCTION}

\section{General aspects}

During the last decades, aquatic molluscs have increasingly excited the interest of ecological science due to their possible role as bioindicators. As documented by numerous studies (Falkner, 1990; Baade, 1993; Sturm, 2000, 2005, 2007; Glöer, 2002; Glöer and Meier-Brook, 2003), diversity of a bio-community consisting of freshwater molluscs commonly depends on a wide spectrum of environmental traits and, therefore, has to be understood as a temporally and locally limited characteristic of an ecosystem. Among the aquatic gastropods and bivalves colonizing a given habitat, generalists with high tolerance to biotic and abiotic factors usually exist together with specialists, which quickly adjust their population density to any modifications of their environment (Glöer and Meier-Brook, 2003; Sturm, 2012). In the past, the capability of such specialists for a fast change of their individual numbers in response to environmental fluctuations has been, among other, used to describe water purity, vegetation density or the grade of naturalness in aquatic ecosystems (Sturm, 2005, 2007). On the other hand, information on the habitat requirements of such indicator species has been crystallized out as useful for both water quality management (Statzner and Sperling, 1993) and water restoration projects (Osborne et al., 1993). Although a comprehensive understanding of the ecology of specialists among the freshwater molluscs in Central Europe would be desirable and helpful in many aspects, studies elucidating optimal environmental conditions demanded by these organisms are limited to few species hitherto (Patzner, 1996; Sturm, 2005, 2007).

\section{Ecological models - a brief overview}

In the past decades mathematical models approximating the ecology of freshwater organisms have experienced rapid expansion in limnologic research (TerBraak and Looman, 1986; Jongman et al., 1987; Peeters and Gardeniers, 1998; Sturm, 2005, 2006, 2013a, 2013b). In principle, three different approaches for the effective description of species-environment relationships have been developed: i) the logistic regression model (Peeters and Gardeniers, 1998; Sturm, 2006); ii) canonical correspondence analysis (CCA; Jongman et al., 1987; Sturm, 2007); and iii) weighted average analysis (WAA; TerBraak and Looman, 1986; Sturm, 2012, 2013a, 2013b). Whilst logistic regression and WAA represent univariate modelling procedures, where the effect of a single environmental factor on a given organism is documented, CAA presents itself as multivariate method, simultaneously describing the influence of all selected environmental factors on the investigated animal or plant. The latter modelling approach bears the advantage that species-environment interaction may be discerned from a single graph, but, on 
the other hand, requires a lot of experience to be interpreted correctly and furthermore includes rather complex mathematics, which may only be processed with specific software (Jongman et al., 1987). Although in the past years all three methods have been applied with similar frequency, WAA has been crystallized out as preferential technique in the case of freshwater malacology, because it provides reliable numerical preference intervals for the regarded factors (Sturm, 2012, 2013a, 2013b). In addition, specific factors enabling the distinction between generalists and specialists occupying ecological niches may be determined on the basis of this technique.

\section{Ecology of the genus Bythinella - state of the art}

Central European spring snails (genus Bythinella Moquin-Tandon 1856, family Hydrobiidae) differ from other aquatic gastropods in several aspects: firstly, adult forms of this genus are characterized by sizes ranging from 1.8 to $3.5 \mathrm{~mm}$ (Fig. 1; Glöer, 2002; Glöer and Meier-Brook, 2003; Sturm, 2005), which remarkably complicates their detection in the field and their reliable determination; secondly, all species described for Central Europe hitherto exhibit endemic behaviour. Whilst Bythinella dunkeri (v. Frauenfeld, 1857) exclusively occurs in Central-German regions located at the Rhine and in a small area of the Black Forest, occurrence of B. compressa (v. Frauenfeld, 1857) is limited to the Rhön and Vogelsberg. B. badensis Boeters 1981 could be described for crystalline formations of the Black Forest as well as those limestone units following in the South. B. bavarica Clessin 1877 chiefly colonizes the Northern-alpine regions between the rivers Lech and Isar, whereas B. austriaca, (v. Frauenfeld, 1857), being in the main focus of this study, occurs in East-Bavaria, the alpine foreland/Northern alps of Tyrol, Salzburg, and Upper Austria, along the Danube, as well as in specific areas of Slovakia, Hungary, Czech Republic, and Poland
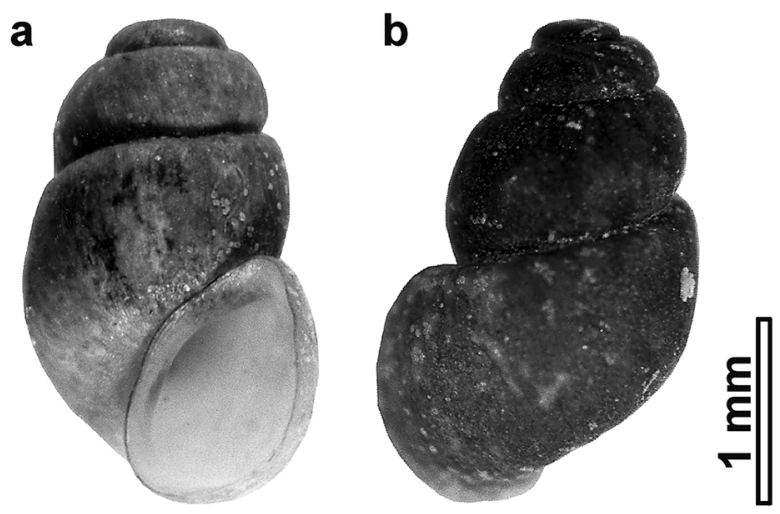

Fig. 1. General appearance of the shell of B. austriaca: (a) front view, (b) back view.
(Boeters, 1973; Jungbluth, 1972, 1973; Meinert and Kinzelbach, 1985; Groh and Fuchs, 1988; Frank et al., 1990; Patzner, 1995; Sturm, 2000; Glöer, 2002; Glöer and Meier-Brook, 2003; Sturm, 2005; Patzner, 2008; Falniowski and Szarowska, 2009). According to Glöer (2002), the species $B$. austriaca includes four sub-species: $B$. austriaca austriaca (v. Frauenfeld, 1857), B. austriaca conica (Clessin, 1910), B. austriaca ehrmanni (Pax, 1938), and B. austriaca pavovillatica (Canon, 1937).

Regarding the ecology of the Austrian spring snail, $B$. austriaca, preliminary results have been outlined by Sturm (2005). According to these data, the gastropod species may be categorized as stenothermic organism preferring cold and clear waters of springs and adjacent brook systems. In such ecosystems, being marked by extremely low contents of nutrients, the Austrian spring snail shows an extraordinary grade of adaptation and, thus, may occur in masses with more than 100 individuals per $\mathrm{m}^{2}$. The snail feeds on different types of algae and bacteria, but also lives from leaves, small pieces of wood, and other organic substances that have been settled down in the water. As also suggested by the theoretical results of Sturm (2005), B. austriaca seems to prefer aquatic habitats with increased content of dissolved $\mathrm{CaCO}_{3}$ in the water, which confines its further dispersal into inneralpine regions.

\section{Main objectives of the present study}

The present contribution pursues three main objectives: Firstly, the modelling approach of WAA is subjected to a detailed description in order to become replicable for the interested reader. Here also two further descriptive factors derived from WAA, namely the global marginality factor (GMF) and the global tolerance factor (GTF), are stated in detail. Secondly, the introduced model and related ecological factors are applied to the Austrian spring snail $B$. austriaca. Selection of this species has been considered as meaningful, because the ecology of this freshwater organism still bears some enigmas. Thirdly, advantages and disadvantages of ecological models are submitted to an intense debate. Here it will be discussed, in what extent results provided by such approaches contribute to general ecology.

The study may be regarded as advancement of a previous work dealing with the habitat preferences of the Austrian spring snail (Sturm, 2005). This first investigation included the modelling of spring snail ecology by simply using high amounts of presence-absence data and computing logistic regression functions. Since goodnessof-fit of respective curves describing the relationship between probability of occurrence and a selected environmental factor is on the order of several percent, ecological predictions conducted with this model are commonly characterized by high inaccuracies. The method 
used in this contribution makes use of counted population density data instead of presence-absence data, which consequently means a remarkable increase in predictive accuracy. The WAA model also represents a sounder basis with regard to the determination and categorization of bioindicator organisms.

\section{METHODS}

\section{Sampling of B. austriaca and measurement of environmental variables}

Fifty-nine sample locations in the county of Salzburg (Austria) and Bavaria including i) the record of B. austri$a c a$ and ii) the measurement of essential environmental variables were used for modelling the ecology of the Austrian spring snail (Fig. 2). In the case of own field work, quantitative sampling of the gastropod species was conducted by using a frequency frame with an area of $0.5 \mathrm{~m}$ x $0.5 \mathrm{~m}$ and collecting/counting all individuals enclosed therein (Sturm 2004, 2007). Besides the exact number of animals per unit area $\left(1 \mathrm{~m}^{2}\right)$, also a categorization of the snail's abundance into four classes was carried out: Class 1 contained all those sample locations, where $B$. austriaca occurred with $<1$ individual per $\mathrm{m}^{2}$, whereas class 2 included sample points with $1 \leq \mathrm{x}<10$ individuals per $\mathrm{m}^{2}$. All sample points with $10 \leq \mathrm{x}<100$ individuals per $\mathrm{m}^{2}$ were assigned to abundance class 3 , whilst class 4 described the occurrence of $B$. austriaca in masses $(\geq 100$ individuals per $\mathrm{m}^{2}$ ).

The following physical and chemical factors were used for the modelling approach: water temperature $\left({ }^{\circ} \mathrm{C}\right), \mathrm{pH}$, electric conductivity $\left(\mu \mathrm{S} \mathrm{cm}^{-1}\right)$, dissolved oxygen $(\mathrm{mg}$ $\left.\mathrm{L}^{-1}\right)$, total hardness of the water $\left(\mathrm{mg} \mathrm{L}^{-1}\right)$, water depth $(\mathrm{m})$, dissolved nitrate $\left(\mathrm{mg} \mathrm{L}^{-1}\right)$, geographic altitude of the sample points $(\mathrm{m})$, biological oxygen demand $\left(\mathrm{BOD}_{5} ; \mathrm{mg}\right.$ $\left.\mathrm{L}^{-1}\right)$ within 5 days, and current velocity $\left(\mathrm{m} \mathrm{s}^{-1}\right)$ of the sampled water. In the case of own field work, measurement of these variables was conducted according to the comprehensive descriptions outlined by Sturm $(2004,2007)$.

Sampling strategy included the two-time collection of animals and measurement of environmental variables within the time interval ranging from May to September. The first session took place in May and June, the second one in August and September. Results of the sessions were combined insofar as mean values for species abundances and environmental variables were determined. Except for $\mathrm{BOD}_{5}$ measurement of environmental variables was carried out by using specific handheld units, an altimeter, and a measuring stick. For determination of $\mathrm{BOD}_{5}$ a water sample was taken and subsequently analysed for its oxygen concentration. Afterwards, the sample was stored in a dark box, transferred to the laboratory and again analysed for its $\mathrm{O}_{2}$ content after five days. Studying the ecology of $B$. austriaca twice a year should help to detect any temporal variability concerning population densities and environmental conditions. As found by comprehensive field studies, number of individuals per sampling site is only insignificantly affected by climatic changes taking place from late spring to late summer. Possible fluctuations of physical and chemical variables determining the habitats colonized by the spring snail may be evaluated as rather moderate and are expressed in part by the standard deviations exhibited in Tab. 1.

\section{Mathematical approach to the ecology of $B$. austriaca}

Weighted average analysis (WAA) represents an easily executable mathematical technique, where site-related data of physical and chemical variables are statistically weighted by the population density of a given species determined at the same sample location. Since locally analysed number of individuals was subjected to an exact quantificaation, the weighting procedure attained its high-

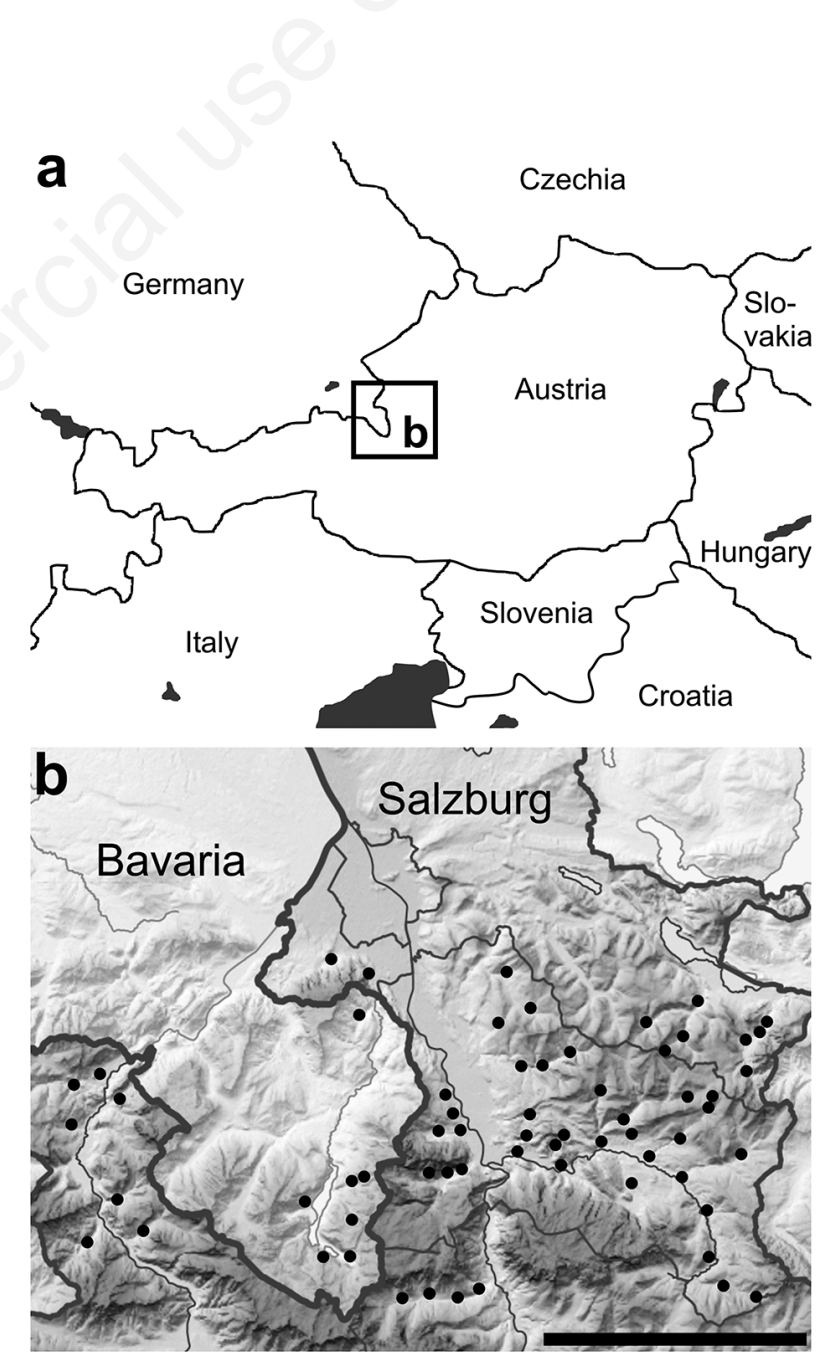

Fig. 2. Geographical map of the sampling area (a) and the single sampling sites (b; black circles) used for this study. The length of the bar in the lower image corresponds to $10 \mathrm{~km}$. 
est level of complexity, which resulted in an optimization of predictive accuracy of the model. The weighted average, $W A$, of a given environmental factor $x$ is calculated according to the formula

$W A=\frac{f_{1} \cdot x_{1}+f_{2} \cdot x_{2}+\cdots+f_{n} \cdot x_{n}}{f_{1}+f_{2}+\cdots+f_{n}}$

where $f_{I}$ to $f_{n}$ denote numbers of individuals at sample site 1 to $\mathrm{n}$, whereas $x_{1}$ to $x_{n}$ represent the measured values of the environmental factor $x$ at sample site 1 to $\mathrm{n}$. The weighted standard deviation, WSD, on the other hand, may be obtained from the equation

$W S D=\sqrt{\frac{N^{\prime} \cdot \sum_{i=1}^{N} f_{i} \cdot\left(x_{i}-W A\right)^{2}}{\left(N^{\prime}-1\right) \cdot \sum_{i=1}^{N} f_{i}}}$.

In the formula noted above $N$ ' represents the number of non-zero population density values, whilst $f_{i}$ denotes the number of individuals determined at sample site $i$.

Based on the WAA conducted for B. austriaca, two coefficients providing more detailed information on the ecological demands of the spring snail were computed (Sturm, 2012). The global marginality coefficient for a certain environmental factor, $G M C_{e f}$, indicates the particularity of a habitat colonized by the focal species and is calculated according to the formula

$G M C_{e f}=\left|\frac{W A_{e f}-M E A N_{e f}}{M E A N_{e f}}\right|$.

In eq. (3), $W A_{e f}$ denotes the weighted average of the environmental factor of interest, whilst $M E A N_{e f}$ represents the mean value of this factor, including all sample points into the statistical computation. As already outlined by Sturm (2012), two categories may be defined for $G M C_{e f}$ : Values of this coefficient $<0.10$ indicate a good agreement between the species-weighted mean value of an environmental factor and the mean value of this factor computed over all measurements and, therefore, express low marginality. Values of $G M C_{e f} \geq 0.10$, on the other hand, indi- cate a non-optimum correspondence between $W A_{e f}$ and $M E A N_{e f}$, resulting in a more remarkable marginality.

The global tolerance coefficient of a given environmental factor, $G T C_{e f}$, commonly expresses the width of a niche occupied by a species and may be obtained from the formula

$G T C_{e f}=\frac{W S D_{e f}}{S D_{e f}}$.

In Eq. (4), $W S D_{e f}$ denotes the weighted standard deviation of a specific environmental factor, whereas $S D_{e f}$ represents the total standard deviation of this factor, including all measurements. As already introduced by Sturm (2012), a $G T C_{e f}>1$ indicates enhanced tolerance of the investigated species with regards to the environmental factor, whereas a $G T C_{e f}<1$ expresses a reduced tolerance of the species concerning this factor (Fig. 3).

The combination of both coefficients allows some conclusions concerning the position of a studied species along the specialist-generalist continuum. An organism characterized by low marginality $\left(G M C_{e f}<0.1\right)$ but high tolerance $\left(G T C_{e f}>1\right)$ for all or most environmental factors may be classified as an ideal generalist. In contrast, an organism marked by high marginality $\left(G M C_{e f}>0.1\right)$ but low tolerance $\left(G T C_{e f}<1\right)$ (Tab. 2) for all or most environmental factors may be categorized as an ideal specialist (Fig. 3).

\section{RESULTS}

\section{Species abundance, environmental data, and WAA}

Statistical computation of abundance recordings including $B$. austriaca came to the result that $48 \%$ of all sample locations bearing the spring snail are characterized by minor abundance of this organism (abundance class 1). Furthermore, $23 \%$ of all sample locations belong to abundance class $2\left(1 \leq \mathrm{x}<10\right.$ individuals per $\left.\mathrm{m}^{2}\right), 25 \%$ of all sample locations to abundance class $3(10 \leq \mathrm{x}<100$ indi-

Tab. 1. Mean and standard deviations of ten environmental factors measured at 59 sample locations with occurrence of $B$. austriaca. Weighted average (WA) and weighted standard deviation (WSD) were computed by including the site-specific abundances of the spring snail into the statistics.

\begin{tabular}{|c|c|c|c|c|}
\hline Environmental factor & WA & WSD & Mean & SD \\
\hline Water temperature $\left({ }^{\circ} \mathrm{C}\right)$ & 10.1 & 2.3 & 11.5 & 3.4 \\
\hline pH-value & 7.6 & 0.4 & 7.5 & 1.2 \\
\hline Elec. conductivity $\left(\mu \mathrm{S} \mathrm{cm}^{-1}\right)$ & 454 & 79 & 341 & 234 \\
\hline Dissolved oxygen $\left(\mathrm{mg} \mathrm{L}^{-1}\right)$ & 10.7 & 1.3 & 9.6 & 1.7 \\
\hline Total hardness $\left(\mathrm{mg} \mathrm{L}^{-1}\right)$ & 243 & 54 & 182 & 116 \\
\hline Water depth (m) & 0.18 & 0.14 & 0.17 & 0.21 \\
\hline Dissolved nitrate $\left(\mathrm{mg} \mathrm{L}^{-1}\right)$ & 1.1 & 1.3 & 2.3 & 1.4 \\
\hline Geogr. altitude (m) & 693 & 225 & 542 & 356 \\
\hline Biol. oxygen dem. (mg L $\left.{ }^{-1}\right)$ & 1.3 & 1.0 & 1.7 & 1.4 \\
\hline Current velocity $\left(\mathrm{m} \mathrm{s}^{-1}\right)$ & 0.81 & 0.39 & 0.49 & 0.36 \\
\hline
\end{tabular}


viduals per $\mathrm{m}^{2}$ ), and the remaining $4 \%$ of the recordings to abundance class 4 ( $\geq 100$ individuals per $\left.\mathrm{m}^{2}\right)$. Statistical treatment of the environmental factors noted in the Methods section is summarized in Tab. 1, including total mean values and standard deviations as well as weighted averages and weighted standard deviations. Regarding water temperature, a total mean of $11.5 \pm 3.4^{\circ} \mathrm{C}$ was measured, whereas weighted average amounted to $10.1 \pm 2.3^{\circ} \mathrm{C}$. Mean $\mathrm{pH}$-value came to $7.5 \pm 1.2$ and weighted average of this environmental factor to $7.6 \pm 0.4$. For electric conductivity, a total mean of $341 \pm 231 \mu \mathrm{S} \mathrm{cm}^{-1}$ and a weighted average of $454 \pm 79 \mu \mathrm{S} \mathrm{cm}^{-1}$ was calculated, whilst respective statistical parameters for dissolved oxygen amounted to $9.6 \pm 1.7 \mathrm{mg} \mathrm{L}^{-1}$ and $10.7 \pm 1.3 \mathrm{mg} \mathrm{L}^{-1}$. Total hardness is characterized by a total mean of $182 \pm 116 \mathrm{mg} \mathrm{L}^{-1}$ and a weighted average of $243 \pm 54 \mathrm{mg} \mathrm{L}^{-1}$, whereas water depth exhibits with $0.17 \pm 0.21 \mathrm{~m}$ and $0.18 \pm 0.14 \mathrm{~m}$ rather similar values for both parameters. A contrary behaviour may be observed for dissolved nitrate, where total mean comes to $2.3 \pm 1.4 \mathrm{mg} \mathrm{L}^{-1}$ and weighted average amounts to $1.1 \pm 1.3$ $\mathrm{mg} \mathrm{L}^{-1}$. For geographic altitude, total mean and weighted average take values of $542 \pm 356 \mathrm{~m}$ and $693 \pm 225 \mathrm{~m}$, respectively. Total mean of the $\mathrm{BOD}_{5}$ came to $1.7 \pm 1.4 \mathrm{mg}$
$\mathrm{L}^{-1}$ and weighted average to $1.3 \pm 1.0 \mathrm{mg} \mathrm{L}^{-1}$. Current velocity of the sampled water amounted to $0.49 \pm 0.36 \mathrm{~m} \mathrm{~s}^{-1}$ (total mean) and to $0.81 \pm 0.39 \mathrm{~m} \mathrm{~s}^{-1}$ (weighted average).

Tab. 2. Marginality and tolerance of $B$. austriaca with respect to the ten environmental factors. Marginality was classified as low for $G M C_{e f}$ adopting values $<0.1$ and as high for $G M C_{e f}$ adopting values $\geq 0.1$. Tolerance was categorized as low for $G T C_{e f}$ values $<0.5$, as medium for values ranging from 0.5 to 1 , and as high for values $>1$.

\begin{tabular}{lcc} 
Environmental factor & Marginality & Tolerance \\
Water temperature $\left({ }^{\circ} \mathrm{C}\right)$ & High & Medium \\
pH-value & Low & Low \\
\hline Elec. conductivity $\left(\mu \mathrm{S} \mathrm{cm}^{-1}\right)$ & High & Low \\
Dissolved oxygen $\left(\mathrm{mg} \mathrm{L}^{-1}\right)$ & High & Medium \\
\hline Total hardness $\left(\mathrm{mg} \mathrm{L}^{-1}\right)$ & High & Low \\
Water depth $(\mathrm{m})$ & Low & Medium \\
\hline Dissolved nitrate $\left(\mathrm{mg} \mathrm{L}^{-1}\right)$ & High & Medium \\
Geogr. altitude $(\mathrm{m})_{\text {Biol. oxygen demand }\left(\mathrm{mg} \mathrm{L}^{-1}\right)}^{\text {High }}$ & Medium \\
Current velocity $\left(\mathrm{m} \mathrm{s}^{-1}\right)$ & High & Medium \\
\hline
\end{tabular}

\section{low marginality}

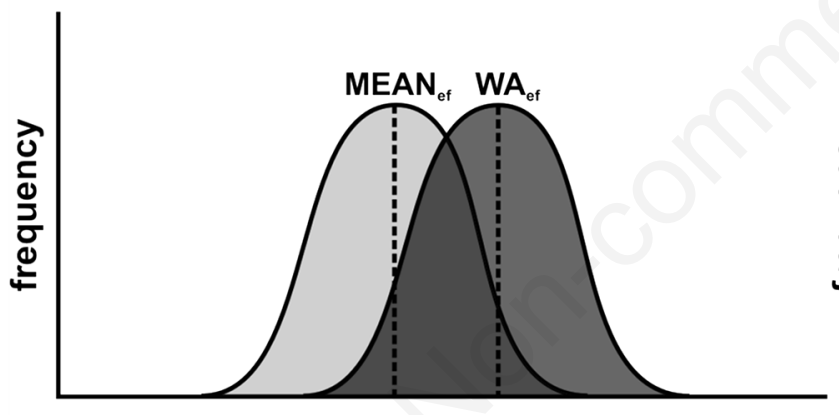

environmental factor

\section{high marginality}

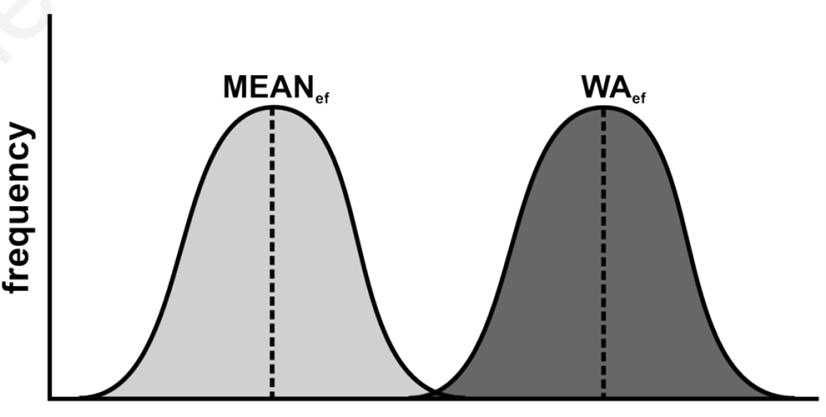

environmental factor

\section{low tolerance}

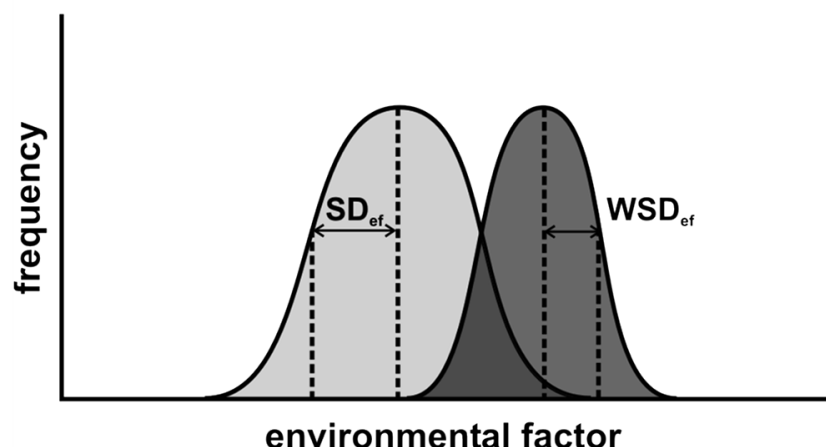

high tolerance

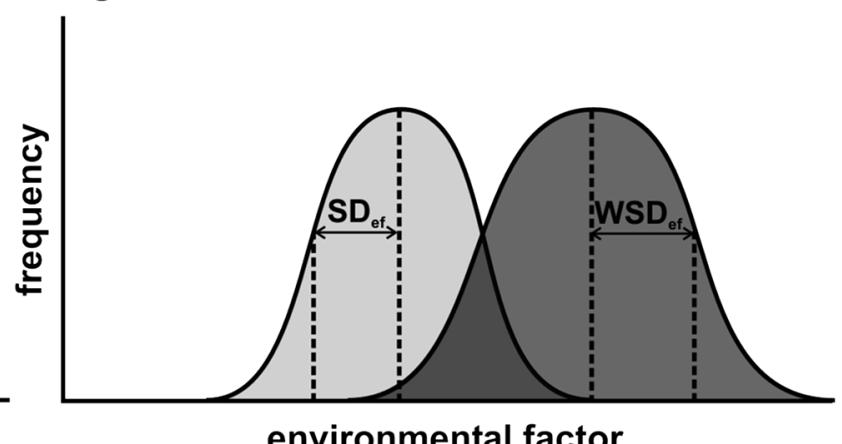

Fig. 3. Graphical illustration of environmental factor distributions obtained from sample location statistics and WAA. For simplicity ideal Gaussian distributions have been assumed. Position of the distributions determines marginality of the species with regard to the environmental factor, whereas width of the distributions represents the main indicator for species tolerance. 


\section{Computation of global marginality and tolerance coefficients}

Statistical data sets described in the previous section were used for the computation of global marginality and global tolerance coefficients in the way stated in the Methods section. Concerning the ability of $B$. austriaca to occupy ecological niches $\left(G M C_{e f} \geq 0.10\right)$, eight environmental factors (water temperature, electric conductivity, dissolved oxygen, total hardness, geographic altitude, dissolved nitrate, current velocity and $\mathrm{BOD}_{5}$ ) underline this specialist behaviour of the spring snail. With regard to the remaining two physical and chemical factors, the gastropod seems to exhibit an increasingly generalist behaviour $\left(G M C_{e f}<0.10\right.$; Fig. 4). The highest global marginality coefficient was calculated for current velocity of the running water $(0.65)$, whereas the lowest coefficient was obtained for water depth (0.05). According to the results illustrated in Fig. 5, B. austriaca is commonly characterized by low tolerances to fluctuations of total hardness, $\mathrm{pH}$-value, and electric conductivity $\left(G T C_{e f}\right.$ $<0.5$ ), whereas intermediate tolerances to changes of water temperature, dissolved oxygen, total hardness, dissolved nitrate, geographic altitude, and $\mathrm{BOD}_{5}$ of the water are determined $\left(0.5 \leq G T C_{e f}<1\right)$. High tolerance of the spring snail could only be found for current velocity of the investigated water $\left(G T C_{e f} \geq 1\right)$.

\section{DISCUSSION}

According to the results obtained from a statistical model with specific parameters for the ecological distinction between generalists and specialists, the spring snail $B$. austriaca may be regarded as significant specialist in some respects. Firstly, the gastropod prefers cold waters with temperatures around $10^{\circ} \mathrm{C}$ and shows intermediate tolerance to any remarkable fluctuations of this environmental factor. This finding, however, corresponds with earlier observations of the snail (Sturm, 2000, 2005) and assumptions regarding its ecological demands (Glöer, 2002; Glöer and Meier-Brook, 2003). It also underlines the fact that $B$. austriaca exhibits highest population densities immediately at the exit of the spring brook from the mountain (Sturm, 2000), whereas the number of individuals usually decreases with any further course of the running water due to a continuous increase of water temperature. Secondly, the spring snail behaves as a specialist with regards to total hardness measured at the sample points and prefers high values of this environmental factor. In the Northern limestone Alps, enhanced values of total water hardness may be regarded as result of high concentrations of $\mathrm{CaCO}_{3}$ dissolved and dissociated in the water. The preference of $B$. austriaca for waters enriched with $\mathrm{CaCO}_{3}$ has main consequences concerning any further dispersal of this species into inner-alpine regions. For

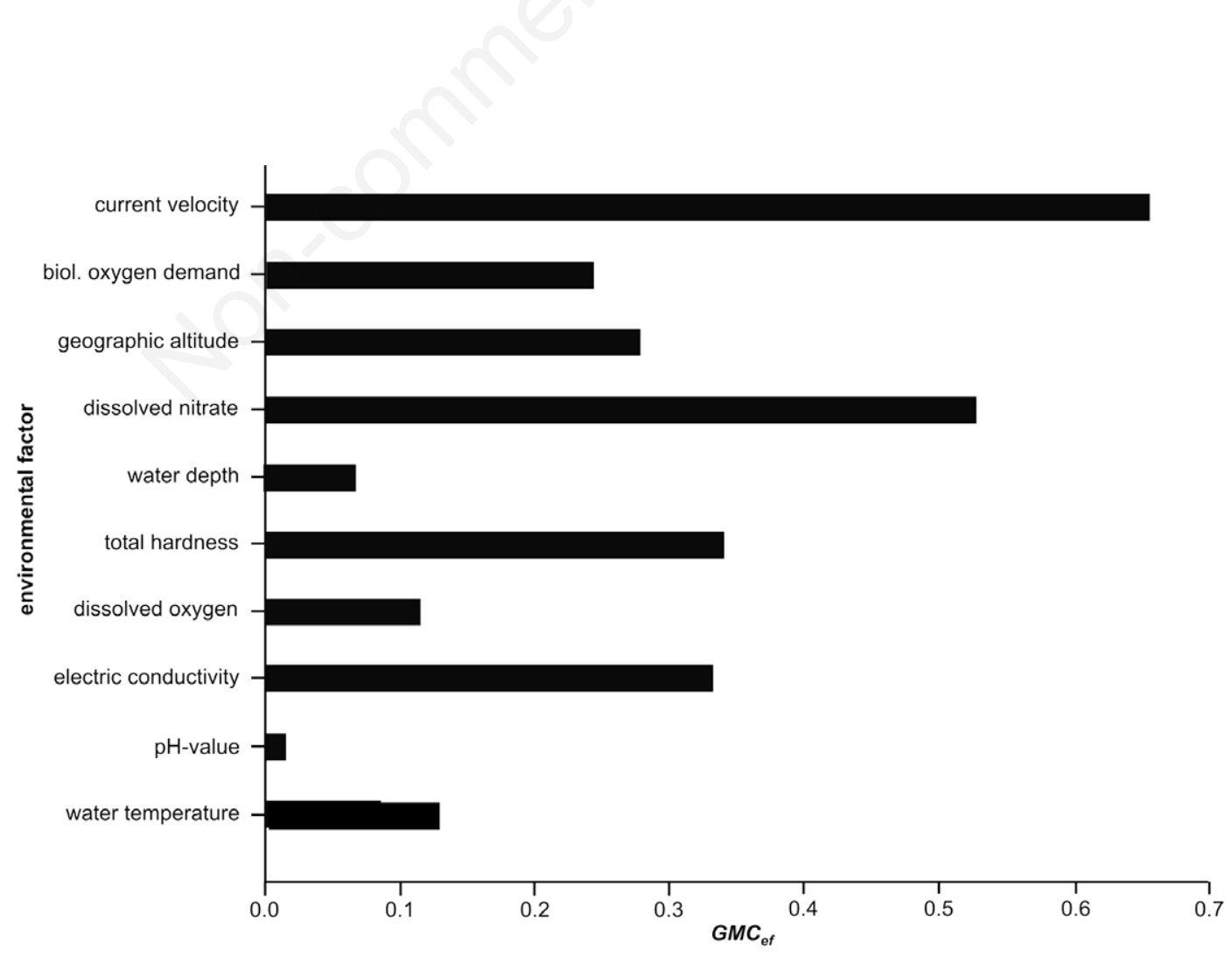

Fig. 4. Results of General Marginality Coefficient computations which were carried out for ten environmental factors. 
the Central-alpine area, records of the spring snail were not reported until now (Frank, 1992, 1996; Sperling, 1975; Sturm, 2004, 2007, 2012, 2013a), which may be explained by the Central-alpine lithology, mainly including silicates. The requirement of waters enriched with $\mathrm{CaCO}_{3}$, however, is not a general demand of spring snails as could be, for instance, reported for $B$. badensis that is found in crystalline areas of the Black Forest (Glöer and Meier-Brook, 2003).

A third characteristic for B. austriaca acting as a specialist concerns its intermediate tolerance with respect to dissolved nitrate in the water. This circumstance, however, seems to awake increased interest, because it represents a basis for the use of the spring snail as an appropriate bioindicator in water quality management. According to the findings presented here and in previous studies (Glöer and Meier-Brook, 2003; Sturm, 1998, 2005), B. austriaca is strictly limited to very clean waters, where any influence by man and specific consequences resulting from that interaction (e.g., increase of algal density and $\mathrm{BOD}_{5}$ ) are kept to a minimum. Another essential result provided by theoretical computations and field observations includes the ability of $B$. austriaca to colonize habitats of the colline and montane altitude level in like manner, as long as water temperature remains on rather low grades. According to previously conducted malacological mappings (Patzner, 1994,

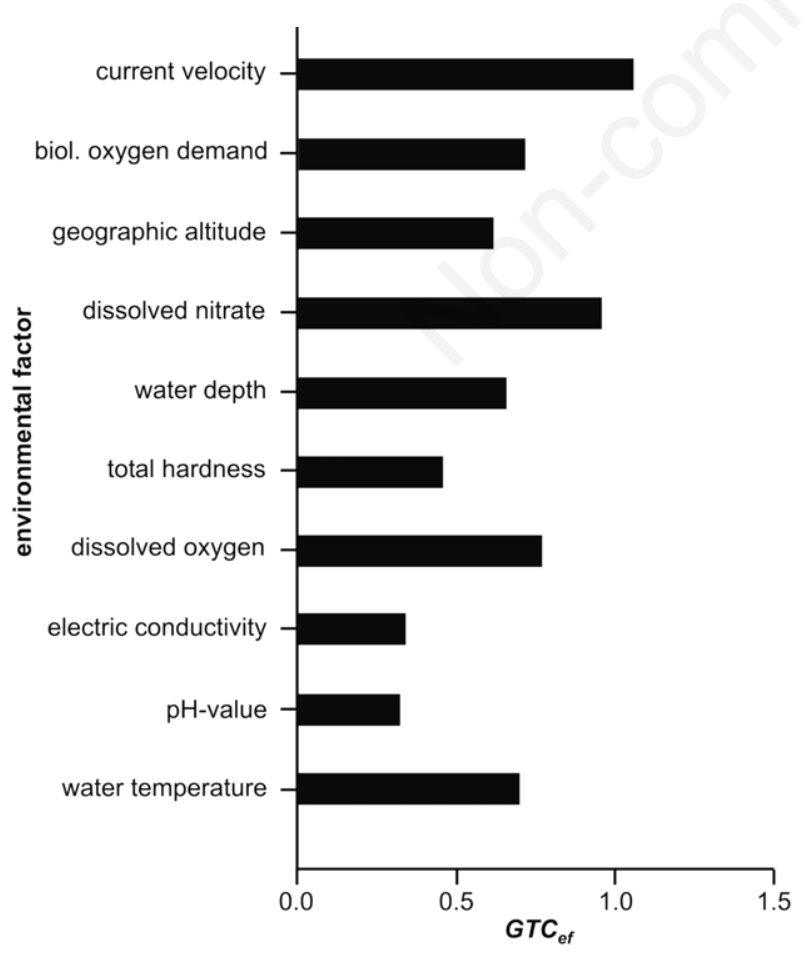

Fig. 5. Results of General Tolerance Coefficient computations that were conducted for ten environmental factors.
1995; Sturm, 1998, 1999, 2005), the Austrian spring snail has already occupied biotopes that are positioned above $1000 \mathrm{msm}$ and may be sporadically found in spring waters which are situated above $1400 \mathrm{msm}$ (subalpine altitude level). Detailed knowledge regarding the colonization of subalpine habitats and a possible maximum altitude of species dispersal, as it is documented for freshwater molluscs in the Swiss Alps (Turner et al., 1998) and parts of the Austrian Alps (Sturm, 2003, 2012, 2013a), still represents a highly desirable scientific aim and should be a main objective of future studies.

According to the model B. austriaca is characterized by high marginality with regard to current velocity of the investigated water, but, at the same time exhibits high tolerance to this environmental factor. Here the model simply expresses the preference of the gastropod for moderately running waters, which among other help to prevent any accumulation of pollutants and largely underline the avoidance of dormant water habitats by the species. The high tolerance to current velocity predicted by the model may be brought into line with the continuous ascend of the spring snail to higher alpine altitude levels, because running waters of these regions are marked by steeper slopes and higher velocities of the flowing waters.

\section{CONCLUSIONS}

From the results presented in this contribution it may be concluded that over far distances WAA represents an appropriate predictive tool for modelling the ecology of a freshwater organism. By using the numbers of individuals collected at a given sample site and implementing them in the descriptive statistics of measured environmental factors, a rather detailed and accurate ecological picture is drawn. Despite these advantages of the mathematical procedure described here, also respective limitations and errors produced by the method have to be kept in mind. The present study only considered B. austriaca colonizing habitats in the Northern alpine regions, but not those individuals of the species living in the alpine foreland. Here significant differences in ecology due to regional adaptive strategies of the organism may arise. Another problem may be given in association with the counting procedure of the individuals and the recording of environmental factors, which both may include noticeable systematic errors. Summing up, it may be stated that WAA bears high potential with regard to regional ecological predictions, but has to be subjected to further applications in order to obtain more general models.

The ecology of B. austriaca bears several specificities, according to which the gastropod receives high value for freshwater biologists. The spring snail, among other, seems to be a reliable indicator for the documentation of environmental pollution and, at the same time, indicates any success of environmental protection. 


\section{REFERENCES}

Baade H, 1993. [Die Molluskenfauna des Stadtgebietes von Altenburg/Thüringen].[Article in German]. Mauritiana 14:55-91.

Boeters HD, 1973. [Die Gattung Bythinella und die Gattung Marstoniopsis in Westeuropa, 1. Westeuropäische Hydrobiidae, 4. (Prosobranchia)].[Article in German]. Malacologia 14:27-85.

Falkner G, 1990. [Binnenmollusken], p. 112-120. In: R. Fechter and G. Falkner (eds.), Weichtiere. [Europäische Meeres- und Binnenmollusken].[Book in German]. Kosmos-Verlag.

Falniowski A, Szarowska M, 2009. Sequence-based species delimitation in the Balkan Bythinella Moquin-Tandon, 1856 (Gestropoda: Rissooidea) with general mixed yule coalescent model. Fol. Malacol. 20:111-120.

Frank C, 1992. [Malakologisches aus dem Ostalpenraum]. [Article in German]. Linzer biol. Beitr. 24:383-662.

Frank C, 1996. [Malakologisches aus dem Ostalpenraum unter besonderer Berücksichtigung südlicher Gebiete 1992-1995]. [Article in German]. Linzer biol. Beitr. 28:75-164.

Frank C, Jungbluth JH, Richnovsky A, 1990. [Die Mollusken der Donau vom Schwarzwald bis zum Schwarzen Meer].[Book in German]. Richnovsky \& Berczik, Budapest: 142 pp.

Glöer P, 2002. [Die Süßwassergastropoden Nord- und Mitteleuropas. Bestimmungsschlüssel, Lebensweise, Verbreitung]. [Book in German]. ConchBooks, Hackenheim: 327 pp.

Glöer P, Meier-Brook C, 2003. Süßwassermollusken. DJN, Hamburg: $138 \mathrm{pp}$.

Groh K, Fuchs H, 1988. [Zum Vorkommen der Quellschnecke Bythinella dunkeri (v. Frauenfeld, 1857) in der Eifel].[Article in German]. Mitt. Dtsch. Malakozool. Ges. 43:19-27.

Jongman RHG, TerBraak CJF, VanTongeren OFR, 1987. Data analysis in community and landscape ecology. Pudoc, Wageningen, $209 \mathrm{pp}$.

Jungbluth JH, 1972. [Die Verbreitung und Ökologie des Rassenkreises Bythinella dunkeri Frauenfeld 1856. (Mollusca: Prosobranchia)].[Article in German]. Arch. Hydrobiol. 70:230-273.

Jungbluth JH, 1973. [Zur Verbreitung und Ökologie von Bythinella dunkeri compressa (Frauenfeld 1856), Mollusca (Prosobranchia)].[Article in German]. Verh. Int. Verein. Limnol. 18:1576-1585.

Meinert W, Kinzelbach R, 1985. [Die Limnischen Schnecken und die Muscheln von Rheinland-Pfalz (Mollusca: Gastropoda et Bivalvia)].[Article in German]. Mainzer Naturwiss. Archiv, Mainz: 58 pp.

Osborne LL, Bayley PB, Higler LWG, Statzner B, Triska F, Iversen TM, 1993. Restoration of low land streams: an introduction. Freshwater Biol. 29:187-194.

Patzner RA, 1994. [Über das Sammeln heimischer Wassermollusken]. [Article in German]. BUFUS-Info 14:7-12.

Patzner RA, 1995. [Wasserschnecken und Muscheln im Bundesland Salzburg. Stand zu Beginn einer landesweiten Kartierung].[Article in German]. Nachrbl. Ersten Vorarlb. Malak. Ges. 3:12-29.

Patzner RA, 1996. [Die Neuseeländische Zwergdeckelschnecke Potamopyrgus antipodarum (Gray 1843) im Bundesland Salzburg].[Article in German]. Linzer biol. Beitr. 28: 1153-1159.
Patzner RA, 2008. [Weichtier des Jahres 2008 - Bythinella austriaca].[Article in German]. Natur und Land, Salzburg: $26 \mathrm{pp}$.

Peeters ETHM, Gardeniers JJP, 1998. Logistic regression as a tool for defining habitat requirements of two common gammarids. Freshwater Biol. 39:605-615.

Sperling P, 1975. [Zur Schneckenfauna des Lungaues (Land Salzburg, Österreich)].[Article in German]. Mitt. Dt. Malak. Ges. 2:269-377.

Statzner B, Sperling F, 1993. Potential contribution of system-specific knowledge (SSK) to stream-management decisions: ecologicalal and economic aspects. Freshwater Biol. 29:313-342.

Sturm R, 1998. [Bericht über Ergebnisse der Süßwassermolluskenkartierung im Tennengau (Bundesland Salzburg)]. [Book in German]. University of Salzburg: $60 \mathrm{pp}$.

Sturm R, 1999. [Die Wasserschnecken und Muscheln in einem Nebenarm der Königsseeache (Bundesland Salzburg). Ein Beitrag zur Wassermolluskenkartierung im Tennengau]. [Article in German]. Linzer biol. Beitr. 31:739-745.

Sturm R, 2000. [Die Süßwassermollusken in Gewässern und Kleinmooren des Postalmgebietes]. [Article in German]. Linzer biol. Beitr. 32:1235-1246.

Sturm R, 2003. Species diversity and abundance of freshwater molluscs (Gastropoda et Bivalvia) in selected mountain lakes of the Central Alps in Austria. Malak. Abh. 21:49-57.

Sturm R, 2004. Freshwater molluscs (Gastropoda et Bivalvia) in selected mountain lakes of the Hohe Tauern, Austria: a contribution to the faunistic mapping of the Eastern Alps. Malak. Abh. 22:23-36.

Sturm R, 2005. Modelling optimum ranges of selected environmental variables for habitats colonized by the spring snail Bythinella austriaca (v. Frauenfeld, 1857) (Gastropoda, Prosobranchia). Malak. Abh. 23:67-76.

Sturm R, 2006. [Habitatansprüche der Süßwasserschnecke Viviparus contectus (Millet, 1813) (Gastropoda: Prosobranchia): theoretische Modellbildung und experimentelle Ergebnisse].[Article in German]. Malak. Abh. 24:19-27.

Sturm R, 2007. Freshwater molluscs in mountain lakes of the Eastern Alps (Austria): relationship between environmental variables and lake colonization. J. Limnol. 66:160-169.

Sturm R, 2012. Aquatic molluscs in high mountain lakes of the Eastern Alps (Austria): Species-environment relationships and specific colonization behaviour. CJOL 30:59-70.

Sturm R, 2013a. [Wie Mollusken die Bergwelt erobern].[Article in German]. BIUZ 43:166-170.

Sturm R, 2013b. Physico-chemical characteristics of habitats colonized by the pond snail Radix labiata (Gastropoda, Basommatophora, Lymnaeidae): a model approach. Linz. biol. Beitr. 45: 2139-2147.

TerBraak CJF, Looman CWN, 1986. Weighted averaging, logistic regression, and the Gaussian response model. Vegetatio 65: 3-11.

Turner H, Kuiper JGJ, Thew N, Bernasconi R, Rüetschi J, Wüthrich M, Gosteli M, 1998. [Fauna Helvetica II: Atlas der Mollusken der Schweiz und Liechtensteins].[Book in German]. Schweizer Entomologische Gesellschaft, Neuchatel: 527 pp. 